\title{
El impacto de la Ley General de Beneficencia de 1822 en Madrid*
}

\author{
Florentina Vidal Galache
}

En 1822, durante el trienio liberal, tiene lugar un hecho trascendental para la historia de la Beneficencia en España. Se trata de la promulgación de la primera Ley General de Beneficencia, que regularía todo lo referente a esta materia, sirviendo además como base para la futura legislación dictada durante el siglo xIX. Su importancia fundamental se debe a que representa el paso definitivo de la Beneficencia a manos de la Administración.

Es en estos momentos cuando se llega al punto culminante de un largo proceso iniciado durante el reinado de Carlos III, por el cual se pretendía dentro de un complejo y bien organizado plan, controlar totalmente la asistencia al necesitado y en algunos casos la represión al pobre ocioso válido para el trabajo, que representaba un peligro potencial para la seguridad ciudadana. Más tarde, como luego veremos, Fernando VII reafirmaría los propósitos de su abuelo promocionando un nuevo plan de Beneficencia. Pero las medidas para que este servicio pasara a ser uno más de los prestados por el Estado a los ciudadanos no son definitivamente afrontadas hasta que se promulga la Ley de 1822.

Tradicionalmente la Beneficencia en España estuvo a cargo de la Iglesia y de los particulares. La labor y competencias del clero en este campo eran plenamente aceptadas por el pueblo y la Monarquía. La Iglesia justificaba las abundantes riquezas que poseía con su labor asistencial que era sin duda alguna cierta.

\footnotetext{
* Este artículo tiene su origen en la investigación realizada para mi Memoria de Licenciatura: "La Beneficencia en Madrid en la crisis del Antiguo Régimen", leída en la UNED el 30 de septiembre de 1986.
} 
A partir del siglo XVI, se plantea en numerosas ocasiones entre los tratadistas del tema las competencias que la Iglesia y el Estado debian asumir en el campo de la Beneficencia. El poderío de la Iglesia, el dominio sobre tierras y otras propiedades fue denunciado en numerosas ocasiones en el Consejo de Castilla ${ }^{1}$. Los detractores del clero acusaban a éste de fomentar la vagancia entre los necesitados y de realizar una caridad "indiscreta" o indiscriminada.

Con la llegada de la dinastía de los Borbones al trono español se producen cambios importantes en aspectos sociales y políticos de la vida del país. La centralización administrativa, el reforzamiento del poder real, la influencia de los llustrados se dejarán sentir rápidamente en las relaciones Iglesia-Estado.

La nueva dinastía francesa pone en marcha una serie de medidas encaminadas a mermar el poderío de la Iglesia, tanto en el aspecto económico como en el político. Entre las primeras se encuentran la recuperación por parte del Estado de los bienes que la Iglesia tradicionalmente dedicaba a Beneficencia. Con la creación de instituciones que sustentaran el plan, como la Real Junta General de Caridad o las Diputaciones de Barrio, se intentaba la total secularización de la asistencia al necesitado con lo que también se mermaba influencia social a la Iglesia.

La puesta en práctica del plan de Beneficencia de Carlos III supuso, pues, que casi todas las competencias referidas a la asistencia pasaran a depender de la Administración. Sin embargo, la fuente principal de financiación continuó siendo la caridad privada -bienes de la lglesia y limosnas de particulares- por lo que el socorro de las necesidades de los pobres siguió dependiendo de la buena voluntad de las clases privilegiadas y ho fue aún asumido como un deber del Estado hacia sus ciudadanos ${ }^{2}$.

\section{LA BENEFICENCIA MADRILEÑA ENTRE 1800 Y 1820}

Durante el primer tercio del siglo XIX se viven en España tiempos muy difíciles. Por ser Madrid la capital del reino, todos los acontecimientos

1 A. Dominguez Ort/z, Las clases privilegiadas en La España del Antiguo Régimen. Madrid. Ed. Itsmo, 1973.

2 La investigación para mi Memoria de Licenciatura, base de este trabajo, se plantea como una continuación de la modélica obra de J. SouBEYroux, Pauperismo y relaciones sociales en el Madrid del siglo XVIII. De ésta han sido tomadas las referencias a los planes de los ilustrados en materia de Beneficencia. 
tienen en esta ciudad una especial repercusión. Es ésta una etapa de transición, en la que existe una pugna entre las ideas reformadoras de los liberales, que tratan de forjar una nueva sociedad, y la permanencia de un pensamiento absolutista, que pretende conservar sus posiciones. La caída de las estructuras sociales del Antiguo Régimen, y la concepción de una nueva sociedad que aún tardaría un tiempo en afianzarse, provocan una aguda conmoción en todos los niveles.

Las crisis de subsistencias, la invasión francesa, la guerra y sus consecuencias, la primera revolución liberal y el retorno del régimen absolutista, repercutieron de forma negativa en la economía, dando lugar a un empobrecimiento generalizado de la sociedad madrileña ${ }^{3}$. La Beneficencia madrileña pasa por duros trances, ya que a los acontecimientos antes señalados, se une una decadencia generalizada de las instituciones creadas en tiempos de Carlos III, que siguen teóricamente cumpliendo sus funciones ${ }^{4}$. También los establecimientos de caridad tradicionales sufren las consecuencias de la crisis económica en la que está sumido el país, no pudiendo por falta de medios o de adaptación hacer frente a las necesidades existentes ${ }^{5}$.

Solamente el plan de Beneficencia promocionado por Fernando VII en 1816, permite pensar que existió una toma de conciencia por parte de la clase dirigente, de los problemas de los necesitados durante esta eta$\mathrm{pa}^{6}$. El plan estaba orientado a aspectos muy concretos -escuelas de primeras letras y hospitalidad domiciliaria- y su puesta en práctica se limitó solamente a la capital.

${ }^{3}$ Sobre este punto consultar; F. VIDAL "La Beneficencia en Madrid, en la crisis del Antiguo Régimen", capítulo 1. Memoria de Licenciatura, 1968. (inédita).

${ }_{4}^{4}$ Las instituciones creadas en tiempos de Carlos III para servir de soporte a su plan de Beneficencia, decayeron en su actividad a principios del siglo XIX, dejando casi totalmente de funcionar durante los años de la Guerra do la Independencia, como queda reflejado en los libros de actas de las Diputaciones de Caridad y de la Junta General de Caridad. Un ejemplo puede ser el Libro de Actas de la Diputación de las Vistillas, años 1804-1805. Archivo de Villa, Sección Secretaría, libro 156.

5 En la "Demostración General de la Población de Madrid" de 1804 (Archivo de Villa, Sección Secretaría 4, leg 4, núm. 4) quedan reflejados un total de 17 hospitales en funcionamiento en la capital. De ellos en un total de 2.483 enfermos hospitalizados, 2.284 lo estaban en los Hospitales General, de la Pasión y de San Juan de Dios, mientras el resto de los hospitales mantenía una media muy baja de hospitalizados.

- La denominación de plan de Beneficencia de Fernando VII al conjunto de medidas tomadas en 1816 referentes a Beneficencia en Madrid, no aparece con este nombre en la documentación de la época. En la documentación aparece separado en dos planes, hospitalidad domiciliaria en todos los barrios de Madrid, y establecimiento de Escuelas Reales en los barrios donde aún no existiese. Archivo de Villa, Sección Corregimiento 1, leg. 222, núm. 19. Lo he demonimado así por considerar que constituyen un proyecto importante en su momento, que continúa el plan establecido por Carlos III. 
Puede deducirse del análisis del plan de Fernando VII, la existencia de un claro continuismo en cuanto a los proyectos de los ilustrados del reinado de Carlos III, cuyo plan, muy amplio, no había llegado a ponerse en práctica en todos sus aspectos. En 1816 se revitalizan antiguas instituciones creadas por Carlos III, la Junta General de Caridad y las Diputaciones de Barrio, que consiguen otra vez, al poner en práctica el plan de Beneficencia de Fernando VII, alcanzar una gran importancia. Las fuentes de financiación continúan siendo las mismas utilizadas desde el siglo anterior, los bienes de la Iglesia y la caridad privada.

Como nota distintiva hay que destacar la prioridad que se daba a la educación, ya que para el sostenimiento de las Escuelas Reales se aportaba una cantidad muy superior a la empleada en hospitalidad domiciliaria ${ }^{7}$. Los beneficiarios, no eran todos los necesitados, sino solamente aquellos cuya actuación se ajustara a unas normas de conducta exigidas por la moral del momento. El pobre ocioso, el mendigo y el vagabundo no eran considerados merecedores de atención, y sí un peligro para la sociedad, por lo que se les encerraba y reprimía.

Por otra parte, los hospitales, hospicios y demás centros de caridad continuaron funcionando de forma precaria, sin que se afrontara para ellos la reforma que ya los ilustrados en la época de Carlos III habían considerado indispensable, pero que no fue llevada a cabo entonces por los graves inconvenientes que presentaba el tema ${ }^{8}$. Estos establecimientos, casi todos de fundación privada, muy antiguos, estaban regidos o administrados en su mayor parte por personajes de gran importancia social, nobles descendientes de los fundadores o investidos en sus cargos por el Rey. La revisión de los establecimientos suponía en muchos casos atentar contra los intereses de estos personajes. La mayor parte de estos centros madrileños había sido fundada para sectores muy concretos de la población, corporaciones, miembros de familias, sacerdotes, etc. Solamente eran públicos el Hospital General para hombres, el de la Pasión para mujeres, el Hospicio que recogía a todos los pobres a partir de los siete años, y la Inclusa y Colegio de la Paz para atender a los recién nacidos y niños hasta los siete años. Estos últimos estaban financiados por rentas que provenían

\footnotetext{
${ }^{7}$ Las cantidades para sostener la hospitalidad domiciliaria eran de 1.650 reales anuales para cada barrio. Para la financiación de escuelas la cantidad era mucho más elevada, 6.000 reales anuales por cada barrio. Fuente: Archivo de la Villa, Sección Corregimiento 1, leg. 222 , núm. 19.

${ }^{8}$ Durante el siglo xVIII, se intentó realizar una reunión de todos los hospitales existentes en Madrid, para conseguir una mejor administración de los fondos y una mejor atención, pero el proyecto quedó interrumpido ante las presiones de patronos y administradores. Para más información consultar J. SOUBYroux, Pauperismo y relaciones sociales en el Madrid del XVIII.
} 
de sus propiedades, limosnas, donaciones reales, pensiones sobre Mitras y otros bienes de la Iglesia, e impuestos con que se gravaban algunos productos de consumo en la Corte. Eran sumamente impopulares entre los menos pudientes, puesto que su mala atención, suciedad y desorden eran del dominio público. La crisis económica por la que atraveśaba el país en estas primeras décadas del siglo XIX afectó de forma muy importante a estos establecimientos que se veían imposibilitados de atender a las numerosas personas necesitadas.

\section{REORGANIZACION LIBERAL DE LA BENEFICENCIA: LA LEY GENERAL DE BENEFICENCIA DE 1822}

Las primeras medidas tomadas por las Cortes liberales, tanto en su política religiosa como en la fiscal, afectaron de forma importante y negativa a los establecimientos de Beneficencia de la capital, que, como decía antes, estaban ya atravesando unas difíciles circunstancias por diversos motivos.

Las medidas contra el clero, como la supresión de órdenes monacales y reforma de regulares ${ }^{9}$, incluía la supresión de todas las órdenes hospitalarias como los Hermanos de San Juan de Dios, los Betlemitas o los Hermanos Obregones que tradicionalmente se habían dedicado a la atención de enfermos en hospitales, realizando una labor ejemplar. Su falta fue rápidamente lamentada ante el vacío creado. Además su dedicación a los pobres y enfermos les hacía ser muy queridos y populares. No existiendo profesionales con quien sustituir a los religiosos poco más tarde se les readmitió ante la necesidad de personal competente para atender a los enfermos ${ }^{10}$. Su posición desde entonces fue la de funcionarios de la Administración y no la de religiosos puesto que sus órdenes habian sido suprimidas.

La pobreza del clero se dejó pronto notar en el campo de la Beneficencia ya que sus bienes seguían en gran parte sirviendo para financiar los gastos de muchos establecimientos. En 1820, la Junta de Señoras que dirigía la Inclusa y Colegio de la Paz, realizaba una angustiosa petición al

\footnotetext{
9 Decreto de supresión de órdenes monacales y reforma de regulares. Decreto de las Cortes de 1 de octubre de 1820. Colección de Leyes y Decretos de las Cortes. Imprenta Nacional. Madrid.

${ }^{10}$ Admisión de Hermanos Obregones para la asistencia a enfermos en hospitales. Archivo, de Villa, Sec. Secretaría 2, leg. 421, núm. 6.
} 
Gobierno, ante la extrema falta de fondos a la que habia llegado el establecimiento. Esta falta de fondos venía, en parte, de que el establecimiento había dejado de percibir cantidades que el Rey le tenía asignadas sobre las Mitras de Orihuela, Segorbe y Granada ${ }^{11}$.

La reducción que el Gobierno efectuó en los impuestos sobre los productos de consumo, aduanas y otros ${ }^{12}$, supuso un grave quebranto para algunos de los establecimientos, como el Hospital General y de la Pasión, que eran los que atendían a la mayor parte de los enfermos sin recursos de la capital. También estos últimos reclamaron ayuda al dejar de percibir estos ingresos. Las Cortes atendieron estas peticiones con bastante rapidez en la Orden de 23 de agosto de 1820 , por la cual se autorizaba al Gobierno “... para que por vía de donación o limosna o cualquier otro título que estime conveniente, compense a estos piadosos establecimientos". Se pedía asimismo al Ayuntamiento que diese razón de todas las fundaciones y memorias que había en la Villa para en cuanto fuese posible atender al socorro perpetuo de los hospitales y demás establecimientos piadosos de la capital ${ }^{13}$. Sin embargo, las medidas tenían un carácter transitorio, y no daban solución a los problemas que desde tanto tiempo atrás venía padeciendo el sistema asistencial madrileño.

\section{La Ley General de Beneficencia de 1822}

La Ley General de Beneficencia fue promulgada por las Cortes Extraordinarias en febrero de 1822. Ampliaba los principios que las Cortes de Cádiz habían consignado en materia de Beneficencia en la Constitución de $1812{ }^{14}$, dando un papel muy importante en su ejecución a los Municipios, y a laś Juntas Municipales de Beneficiencia y a las Juntas Parroquiales como auxiliares de los primeros. Las Diputaciones quedaban encargadas por la Ley de inspeccionar las cuentas presentadas por los Ayuntamientos antes de que éstas pasaran al Gobierno. También debían proponer al Go-

11 Petición de la Junta de Señoras de la Inclusa al Gobierno, incluida en Orden de las Cortes de 17 de octubre de 1820. Colección de Leyes y Decretos de las Cortes. Imprenta Nacional. Madrid.

12 Los arbitros piadosos sobre derechos de aduanas quedaron suprimidos por Real Or den de 1 de enero de 1821. Archivo de Villa, Sec. Secretaria 2, leg. 168, núm. 178.

Sobre la reducción en la contribución general consultar: F. SUAREZ, López Ballesteros y la Hacienda entre 1823 y 1832, tomo 1, pág. 23.

${ }_{13}$ Orden de las Cortes de 23 de agosto de 1820. Archivo de Villa, Sec. Secretaría 2, leg. 168, núm. 180.

${ }^{14}$ Ley General de Beneficencia promulgada el 6 de febrero de 1822. Colección de Leyes y Decretos de las Cortes. Tomo XX. págs. 119-137. Imprenta Nacional. Madrid.

Constitución de 1812. Tít. VI, Cap. l, art. 321. Opus. cit. 
bierno los medios para ir estableciendo el plan de Beneficencia en sus respectivas provincias.

La gran importancia que en esta etapa alcanzan los Municipios se justifica dentro de una nueva concepción de la organización del territorio. En la nueva organización liberal, el Municipio, debía ser una institución que sirviese como medio de participación ciudadana en el Gobierno. Los liberales veían igualmente la posibilidad de los Ayuntamientos representativos como medio de penetración de las nuevas ideas y de atracción de la población. La representatividad quedaba garantizada, ya que todos los cargos eran elegidos por los vecinos. Los cargos municipales eran gratuitos, cada año se renovaban los alcaldes y la mitad de los concejales. La únicas restricciones venían dadas por la obligación de rendir cuentas a las Diputaciones de la recaudación e inversión de los fondos públicos, así como de la aprobación de las Cortes, a través de las Diputaciones, para toda nueva imposición de arbitrios destinadas a obras u otros objetos de utilidad ${ }^{15}$. Estas restricciones limitaban de forma sustancial las funciones de los Municipios, y tuvieron una importancia fundamental, como luego veremos en la aplicación de la Ley de Beneficencia en el Municipio de Madrid.

La Ley General de Beneficencia de 1822 sistematizó todos los aspectos de la Beneficencia, dando el paso definitivo para que este servicio quedase por entero en manos de la Administración. Para ello, la medida fundamental fue hacer pasar todos los bienes de Beneficencia a un fondo común, que más tarde se dividiría según los fines, en bienes municipales o generales ${ }^{16}$. También la conversión de bienes y establecimientos privados de beneficencia en públicos ${ }^{17}$. Con esta medida debía darse fin a los abusos que los administradores y patronos de establecimientos privados venian efectuando desde largo tiempo atrás, haciendo que los medios que estos utilizaban para su interés particular pasaran a engrosar los de la Beneficencia pública.

Al hacerse cargo el Gobierno del déficit resultante en los gastos de los establecimientos públicos queda ya totalmente asumida por el Estado la obligación de atender a la Beneficencia como un servicio más al ciudadano ${ }^{18}$.

${ }^{15}$ Para más información sobre el tema de los Municipios liberales consultar: C. CASTRO, La revolución liberal y los municipios españoles. Madrid. Ed. Alianza, 1985.

${ }^{16}$ Ley General de Beneficencia, Tit. 2, art. 26. No existiendo actualmente ningún análisis de la Ley General de Beneficencia de 1822, mi trabajo constituye una aportación en este aspecto tan poco conocido. Como obra de consulta referida a este tema, durante el siglo XIX sigue siendo interesante la obra de F. HeRnANDEZ IgLESIAS, La Beneficencia en España. Madrid. Imprenta Minuesa, 1876.

17 Ibidem. Tit. VIII, art. 129.

${ }^{18}$ Ley General de Beneficencia, Tit. VIII, art. 136. 
Aspectos destacables de esta primera Ley son, entre otros: la municipalización de la Beneficencia; la reforma hospitalaria, que afronta la necesaria revisión de todo el sistema, tan necesaria desde mucho tiempo atrás; la creación de casas de maternidad, hospitales para locos y convalecientes. La correción de abusos y concesión de libertad a los pobres del hospicio, que en estos momentos toma el nombre de casa de socorro, sin duda para dejar bien claro la orientaçión totalmente distinta que los liberales quieren dar a estos establecimientos, que durante muchos años habian servido tanto como asilo para los pobres desvalidos como centro de represión para aquellos necesitados a los que se consideraba válidos para el trabajo, para los mendigos y los delincuentes menores.

En la Ley queda contemplada la continuidad de asociaciones caritativas y religiosas que en el período anterior hubieran desarrollado una labor asistencial positiva ${ }^{19}$, quedando desarticuladas las instituciones que los ilustrados habían creado para sustentar y dirigir la asistencia, como la Junta General de Caridad y las Diputaciones de Barrio, pasando sus competencias a las Juntas Municipales y Parroquiales recién creadas ${ }^{20}$.

Se aprecia en los objetivos planteados por la Ley, un evidente continuismo en muchos temas fundamentales, con respecto al pensamiento ilustrado. Se pueden citar: la importancia dada a la hospitalidad y socorros domiciliarios, que fue una constante en los planes de los ilustrados, justificada por el hecho de la falta de puestos hospitalarios y la mejor utilización de recursos y mejores resultados con este sistema. Los liberales lo continúan, poniéndolo en manos de las Juntas Parroquiales de Beneficencia.

Asimismo se sigue dando una gran importancia a las escuelas de primeras letras y a la regeneración del pobre por el trabajo en las fábricas de la casa de socorro, con creación en éstas de nuevos puestos de trabajo.

19 Un ejemplo son las Hermanas de la Caridad, y otros religiosos de órdenes hospitalarias; en cuanto a asociaciones, la Junta de Damas Nobles, que desde principios de siglo estaban encargadas de la dirección y administración de la Inclusa y Colegio de la Paz y que como veremos más adelante fueron confirmadas por la Junta Municipal de Beneficencia de Madrid, en sus funciones.

${ }^{20}$ Las Juntas Parroquiales de Beneficencia habian actuado en Madrid de forma tradicional, con el nombre de Juntas Parroquiales de Caridad, financiadas solamente con las limosnas de los feligreses, y $\sin$ apoyo ninguno por parte de la Administración. La Ley parece reconocer la labor asistencial llevada a cabo durante tantos años, encargando a éstas de la hospitalidad domiciliaria. 


\section{EL IMPACTO DE LA LEY EN EL MUNICIPIO DE MADRID}

\section{La Junta Municipal de Beneficencia}

Para poner en práctica lo dictado por la Ley General de Beneficencia, se constituyó en Madrid, el 31 de marzo de 1822 la Junta Municipal de Beneficencia. La Ley concedía a ésta amplios poderes como auxiliar del Ayuntamiento. La Junta ${ }^{21}$, presidida por el alcalde primero constitucional, marqués de Santa Cruz y siete miembros más, contaba entre éstos con personas que habían desempeñado puestos importantes en materia de Beneficencia en los años anteriores ${ }^{22}$. La continuidad de éstos en puestos similares a los que habían desempeñado en la anterior época absolutista parece indicar que existía por parte de los liberales una intencionalidad práctica y constructiva en lo referente a los temas de Beneficencia.

En el corto período de tiempo en que se desarrolla la actividad de la Junta, 31 de marzo de 1822 a 25 de mayo de 1823, se aprecia en las actas de las sesiones la dedicación y el entusiasmo con que sus miembros llevaron a cabo las tareas que les habían sido encomendadas. Muy respetuosos en el cumplimiento de la Ley, encontraron numerosas dificultades para su puesta en práctica, algunas de las cuales hay que enunciar brevemente.

\section{Los apuros financieros de la Junta}

La falta de medios económicos para atender el déficit que los establecimientos públicos tenían en esos momentos, tras las precipitadas medidas tomadas por las Cortes en su primera legislatura, se vio en teoría

${ }^{21}$ La primera Junta Municipal de Beneficencia estaba compuesta por: el marqués de Santa Cruz, como alcalde primero constitucional; Antonio Ruiz como regidor del Ayuntamiento; Juan Antonio Salcedo como párroco más antiguo de la capital; José Molina Rodríguez, capellán de las Descalzas Reales; Juan Blasco Negrillo, coronel del Ejército; Francisco Carreras, abogado de los Tribunales Nacionales; José Antonio Piquer, médico y Bonifacio Gutiérrez, cirujano. Fuente: Libro de actas de la Junta Municipal de Beneficencia de Madrid, entre 1822 y 1823. Archivo de Villa, Sec. Secretaría. Libro 186. Estos documentos, y todos los consultados en la Sección de Corregimiento y Beneficencia del citado Archivo han servido esencialmente de fuentes documentales para realizar este trabajo.

${ }^{22}$ El marqués de Santa Cruz habia formado parte de la Real Junta de Hospitales desde 1803 hasta 1820; Juan Antonio Salcedo era miembro de la Real Junta General de Caridad, hasta su extinción en 1821; Antonio Ruiz perteneció desde su fundación a la Real Sociedad Económica Matritense. Fuente: Guía de Forasteros, años 1808, 1817 y 1821; Actas de la Real Sociedad Económica de Amigos del País, año 1780. 
solucionado por el Decreto de las Cortes de 23 de febrero de $1822{ }^{23}$ por el que se devolvía a los hospitales, hospicios y demás casas de Beneficencia los bienes que les habían sido incautados por el Decreto de 20 de marzo de 1820. Para solucionar la situación entonces creada, se destinaba a cubrir el déficit que resultara para sostener los establecimientos de Beneficencia de la nación el producto de la Bula de Cruzada sin perjuicio de la aplicación de su quinta parte al pago de los intereses de la deuda nacional. Hasta que ese déficit pudiese cubrirse completamente de la forma expresada o con otros recursos que les concediesen las Cortes se aplicaban a la Beneficencia pública los siguientes arbitrios: la mitad del diez por ciento de Propios...; el rendimiento del indulto cuadragesimal; el producto del fondo pío beneficial; una manda forzosa sobre los testamentos y un impuesto adicional sobre cruces, condecoraciones y otros honores concedidos por el Rey.

La Junta Municipal de Beneficencia madrileña contaba para atender a los establecimiento a su cargo, que eran en estos momentos el Hospital General, el Hospital de la Pasión, la Inclusa y Colegio de la Paz, y la Casa de Socorro (antes Hospicio) con una asignación que mensualmente le pasaba el Ayuntamiento. Esta ascendía a 166.000 reales, cantidad totalmente insuficiente para atender las necesidades de los establecimientos. Por otra parte debia percibir las cantidades que produjeran los arbitrios antes citados.

En la práctica las asignaciones que debía pasar el Ayuntamiento se retrasaban con una relativa frecuencia llegando a producir grandes trastornos al no poder la Junta atender a sus obligaciones con los establecimientos. Por otra parte, las cantidades procedentes de los arbitrios antes citados, no eran ni fijas ni seguras, no llegando de hecho a cobrarse durante el tiempo de actuación de la Junta ninguna cantidad en concepto de producto del fondo pío beneficial, como se deduce al estudiar las actas de sus sesiones.

A partir de la primera sesión de la Junta se hacen patentes los apuros por los que estan pasando todos los establecimientos a su cargo. El presidente de la extinguida Junta de Hospitales, marqués de las Hormazas expone la absoluta falta de fondos por la que atraviesa el Hospital General y pide se tomen urgentes medidas para remediar la situación ${ }^{24}$. En los mismos términos se producen en las siguientes sesiones las peticiones de todos los demás establecimientos.

${ }^{23}$ Decreto de las Cortes de 23 de febrero de 1822. Colección de Leyes y Decretos de las Cortes Imprenta Nacional. Madrid.

24 Sesión celebrada el 31 de marzo de 1822. Libro de actas de la Junta Municipal de Beneficencia. pág. 3, Archivo de Villa. Sec. Secretaría, Libro 186. 
Las peticiones de ayuda al Ayuntamiento, a la Diputación y al Gobierno quedan sin respuesta, o al menos éstas llegan tarde. La burocracia retrasa las posibles soluciones que los miembros de la Junta proponen al Gobierno ${ }^{25}$. El 5 de agosto de 1822, la Junta, tras reclamar varias veces sin obtener respuesta la asignación que el Ayuntamiento debe pasarle mensualmente, presenta la dimisión ante la imposibilidad de continuar con su labor por falta de fondos. El Ayuntamiento le envía la asignación y la Junta prosigue su tarea, aunque esta situación continúa repitiéndose hasta el final de su actuación.

\section{Dificultades para el cumplimiento de la Ley}

En cumplimiento del artículo 12, título 1 de la Ley, la Junta debía reunir la estadística de los establecimientos de su distrito. Como ya había sucedido en otras ocasiones, la dificultad para reunir estos datos que dieran cuenta de los establecimientos de caridad de Madrid, sus estatutos, la labor desarrollada, etc. fue muy grande. Existía gran resistencia por parte de los administradores y protectores de los distintos centros a facilitar la documentación, por si en ella quedaban reflejadas noticias que pudieran perjudicar sus intereses privados.

La Ley dejaba claramente expresado en sus artículos 129 y 131 del título VIII: "Cuando los establecimientos de fundación privada hubiesen sido fundados exclusivamente para socorro de alguna familia, corporación, ...se propondrá por las Juntas de Beneficencia a los interesados en su conservación la cesión del derecho que pueda corresponderles, ofreciendo iguales ventajas en los establecimientos análogos del pueblo o provincia al que pertenezcan; y si conviniesen en ello se agregarán sus haberes al fondo común de Beneficencia cuidando las Juntas de cumplir escrupulosamente lo pactado". "Si no conviniesen en ello no se admitirán a los miembros de aquellas familias, corporaciones. ... mientras no esté lleno el objeto de su fundación y en todo caso quedarán obligados a observar las leyes y reglamentos en el nuevo sistema y presentar a la Junta Municipal de Beneficencia sus cuentas, únicamente para examinar si se cumple lo dispuesto por sus fundadores, y cuidar se lleve a debido efecto su voluntad".

${ }^{25}$ Cuando las Cortes, en mayo de 1823 deciden oir a la comisión de Beneficencia del Ayuntamiento, que había solicitado tiempo atrás proponer arbitrios para Beneficencia, la comisión se habia disuelto, no quedando en el Ayuntamiento más que uno de sus miembros. Archivo de Villa. Sec. Secretaría 2, leg. 334, núm 23. 
En ningún caso, que conste en las actas, se produjo cesión de derechos por parte de los interesados, para que sus establecimientos pasaran a ser públicos ${ }^{26}$. Declarados todos ellos de patronato particular, quedaron sujetos a la inspección de sus cuentas y cumplimiento de sus obligaciones, por parte de la Junta Municipal de Beneficencia. La reunión de todas las noticias para completar la estadística de los establecimientos madrileños tardó en completarse desde abril hasta diciembre de 1822.

Una resistencia parecida encontró la Junta al reclamar las cuentas y fondos de las extinguidas Diputaciones de Barrio, que debían pasar a manos de las Juntas Parroquiales de Beneficencia para que estas últimas atendieran a la hospitalidad y socorros domiciliarios. La financiación de esta asistencia debían realizarla las parroquias con las suscripciones y limosnas entregadas con tal fin por los feligreses. Como su función era una continuación de la realizada por las Diputaciones de Barrio en la etapa absolutista, los fondos que éstas conservaban en el momento de su extinción fueron destinados a las Juntas Parroquiales. El 23 de febrero de 1823 la Junta Municipal recurrió el Ayuntamiento para que reclamara a las Diputaciones los fondos que éstas no querian entregar. Finalmente, cuando las Diputaciones hicieron entrega de sus efectos, trasladaron también a la Junta las deudas contraídas, por lo que en muchos casos fueron muy pocos los fondos que por este concepto llegaron a las Juntas Parroquiales.

\section{La labor de la Junta Municipal de Beneficencia}

En el artículo 12, título 1 dice que entre las obligaciones de la Junta estaba: "Hacer observar esta Ley y Reglamentos y Ordenes del Gobierno a Directores, Administradores y demás empleados de los establecimientos de Beneficencia". La Junta, a través de los distintos visitadores, miembros de la misma, realizaba las inspecciones en los distintos establecimientos, encontrando en algunos casos resistencia, por parte de los administradores, al cumplimiento de la Ley, como consta en el acta de la sesión celebrada el 11 de septiembre de 1822. En ella Francisco Carreras, visitador de la Casa de Socorro manifestaba que: “... renunciaba a su calidad de visitador ante los desaires que experimenta y la falta de decoro a la Junta por parte del Director". Se deduce de lo dicho que el Director no facilitaba

${ }^{26}$ Un ejemplo de municipalización temporal de una fundación de Beneficencia particular al amparo de la Ley de 1822 ha sido estudiado en la Memoria de Licenciatura de Manuel SANCHEZ GOMEZ-CORONADO: El Hospital de Santiago en la Villa de Zafra en la transición del Antiguo Régimen, leida en la UNED en octubre de 1986. 
la labor del visitador, presentando toda clase de inconvenientes y negándose a contestar a las preguntas que éste le hacía.

Todas las semanas se pasaba un informe de los hospitales públicos, Inclusa y Colegio de la Paz, que contenía el "estado de enfermos", gastos, cuentas y demás información. La Casa de Socorro presentaba sus cuentas una vez al mes, al tiempo que el número de asilados, etc. Estas una vez revisadas por la Junta eran aceptadas o devueltas al establecimiento correspondiente para una mayor especificación. Más tarde se pasaban todas ellas al Ayuntamiento para su aprobación. En la etapa que cubre la actuación de la Junta, las cuentas fueron presentadas con puntualidad y siguiendo los trámites previstos en el apartado 5 del artículo 12, título 1 de la Ley.

Con referencia a la hospitalidad pública, hay que señalar la admisión de las Hermanas de la Caridad para atender a los enfermos del Hospital de la Pasión, según consta en las actas del 6 de abril de 1822. Más tarde serían admitidos los Hermanos Obregones para atender enfermos en el Hospital General.

La Junta de Señoras fue confirmada en sus anteriores funciones como directora y administradora de la Inclusa y del Colegio de la Paz. Esta asociación con el nombre de Junta de Damas Nobles venía desempeñando estas mismas funciones desde principios de siglo, con excelentes resulta$\operatorname{dos}^{27}$.

Se realizaron por iniciativa de la Junta mejoras en las condiciones higiénicas del Hospital General, trasladando la sala de disección de dicho centro, que se encontraba contigua a las salas de enfermos, al antiguo edificio del Hospital de San Juan de Dios destinado en esos momentos a almacén del Ejército.

Quedaron suprimidas a petición de la Junta las antiguas cátedras de cirugía, ya que entraban en conflicts con la nueva Ley de Enseñanza.

En cuanto a la corrección de abusos en los distintos establecimientos, constan en las actas las denuncias hechas por los visitadores del Hospital General y de la Inclusa. El primero, en la sesión celebrada el 23 de abril denunciaba la discriminación sufrida por algunos enfermos, en las salas del Hospital. El visitador de la Inclusa, hizo saber en la sesión celebrada el día 30 de abril, que un niño había muerto y otro había quedado tuerto a

${ }^{27}$ Sobre la Inclusa y la dirección de la Junta de Damas Nobles, consultar el artículo de P. Demerson: "La Real Inclusa a finales del XVIII", en Anales del Instituto de Estudios Madrileños, tomo VIII. Madrid, 1972, págs. 261-272. 
consecuencia de los malos tratos sufridos por las criaturas a manos de los dependientes del establecimiento. En ambos casos se declaró por parte de la Junta la intención de intervenir para corregirlos, pero no consta en las actas ninguna acción tomada en este sentido.

La Ley General de Beneficencia no pudo ser puesta en práctica en todos sus aspectos, en el Municipio de Madrid, a pesar de la dedicación y buena voluntad que los miembros de la Junta Municipal de Beneficencia pusieron en conseguirlo. La falta de fondos para afrontar cualquier mejora, la dependencia de la Junta con respecto al Ayuntamiento y a la Diputación a la hora de tomar decisiones, la resistencia por parte de los patronos y administradores a que la Ley fuese impuesta en los distintos establecimientos, el escaso tiempo de actuación, y la inestabilidad política de estos momentos contribuyeron sin duda a que su labor no llegase a completarse. No obstante, su significado tiene una importancia fundamental como primer paso o base para futuras actuaciones. La Ley, como decia antes, sirvió como punto de partida para la legislación sobre Beneficencia dictada durante todo el siglo XIX. Las circunstancias políticas que vivió el país en la siguiente etapa absolutista hicieron que las reformas iniciadas quedaran abandonadas, para ser de nuevo revisadas en la siguiente etapa liberal. 